\title{
Accidental ingestion of poisons and child personality
}

\author{
J. R. SIBERT \\ M.A., M.B., M.R.C.P., D.C.H. \\ Departments of Child Health and *Medical Statistics, \\ University Hospital of Wales, Heath Park, Cardiff
}

R. G. NEWCOMBE*

\begin{abstract}
Summary
The personality of 105 children under 5 years of age admitted to Cardiff Hospital was compared with 105 control children by means of a semantic differential test. Poisoning-children were significantly more anxious $(P<0.008)$, harder $(P<0.01)$, and more active $(P<0.04)$ than controls. They also caused more worry $(P<0.04)$ and put other than food more often in their mouths $(P<0.002)$.

There were no significant differences in the age of walking, and the ages of becoming clean and dry between cases and controls. However, poisoningchildren had significantly more accidents and hospital admissions than did controls. The relevance of these findings, particularly in relation to the important role of family stress, to the aetiology of accidental poisoning in childhood is discussed.
\end{abstract}

\section{Introduction}

Why children under 5 years should take poisons accidentally is by no means certain. Availability of the poison in the child's home does not appear to be an aetiological factor (Baltimore and Meyer, 1969); however, there may be trends in both family and child that predispose to poisoning incidents. Family stress has been shown to be important in the causation of road accidents in children (Backett and Johnston, 1959; Burton, 1968), and also in childhood poisoning (Sobel, 1971).

Factors in the child predisposing to childhood poisoning were investigated by Margolis (1971), who studied children 5 years after they took poisons. He suggested that children with a tendency to hyperactivity, destructiveness and unco-operativeness were more likely to take poisons than were controls. Stewart, Thach and Freidin (1970) also found that hyperactive children were prone to take poisons. Sobel (1971) looked at children and their families in a large community study, comparing children who had poisoning incidents in the past with those who had not. Although the majority of this work was concerned with maternal psychopathology and stress, he also looked at aspects of child psychopathology and personality as well. Of his nine scales of child psychopathology only one (sexual preoccupation) showed significant differences between poisoningchildren and controls at the $P<0.05$ level of statistical significance. Looking at the relation between mother and child the only significant difference at the $P<0.05$ level was that poisoningchildren had more power struggles with their mothers than did controls.

Because of this background a retrospective study was undertaken in a British community investigating aetiological factors in childhood poisoning. Family stress was shown to be a highly significant factor in the poisoning incidents (Sibert, 1975), in addition the personality and development of the poisoning-children was compared to controls, and it is these data that are presented here.

\section{Methods and results}

One hundred and five children under 5 years of age admitted to Cardiff Hospitals having ingested poisons in 1974 were compared to control children matched for age, sex and socio-economic class, whose names were obtained from the Cardiff Birth Survey. Of the 105 poisoning-children there were fifty-four boys and fifty-one girls. Their ages ranged from 8 months to 4 years 10 months, with a mean of 31.8 months. Altogether twenty-seven of the children took salicylates (all but two of which were one brand of acetylsalicylic acid tablets, Junior Aspirin), fiftysix took other drugs, fourteen took domestic poisons, six took hydrocarbons and two took laburnum berries. The parents of the poisoningchildren were interviewed within 1 week of the incident. They, and the parents of the controls, were asked to give information on their children's personality by means of a semantic differential test modified from Osgood, Suci and Tanenbaum (1957). The semantic differential has been used since 1957 for a variety of situations particularly for assessing personality (Sarason, 1972). Parents graded their children's personality on a series of seven-point scales, each defined by adjectives opposite in meaning. For instance, using the first of these scales, delicate to tough, a score of 1 would indicate that the child was considered very delicate, and a score of 7 very tough. Scores between 2 and 6 would indicate a 
gradation between these extremes. The scales used, together with the mean scores of poisoning-children and controls, are shown in Table 1.

TABLE 1.

\begin{tabular}{lcc}
\hline \multicolumn{1}{c}{ Concept } & $\begin{array}{c}\text { Mean } \\
\text { score } \\
\text { poisoning- } \\
\text { children }\end{array}$ & $\begin{array}{c}\text { Mean } \\
\text { score } \\
\text { controls }\end{array}$ \\
\hline 1 Delicate-tough & $5 \cdot 81$ & $5 \cdot 58$ \\
2 Eating well-choosey & $3 \cdot 19$ & $3 \cdot 22$ \\
3 Rough-gentle & $3 \cdot 16$ & $3 \cdot 34$ \\
4 Confident-timid & $2 \cdot 54$ & $2 \cdot 92$ \\
5 Anxious-relaxed & $4 \cdot 10$ & $5 \cdot 06$ \\
6 Noisy-quiet & $2 \cdot 04$ & $2 \cdot 46$ \\
7 Happy-unhappy & $1 \cdot 53$ & $1 \cdot 37$ \\
8 Insecure-secure & $5 \cdot 46$ & $6 \cdot 04$ \\
9 Independent-dependent & $2 \cdot 18$ & $2 \cdot 09$ \\
10 Bad-good & $4 \cdot 87$ & $5 \cdot 24$ \\
11 Calm-excitable & $4 \cdot 74$ & $4 \cdot 71$ \\
12 Strong-weak & $1 \cdot 88$ & $1 \cdot 74$ \\
13 Submissive-aggressive & $4 \cdot 88$ & $4 \cdot 43$ \\
14 Active-passive & $1 \cdot 31$ & $1 \cdot 72$ \\
15 Isolated-sociable & $5 \cdot 89$ & $5 \cdot 90$ \\
16 Generous-selfish & $2 \cdot 71$ & $2 \cdot 54$ \\
17 Puts things other than food in & & \\
mouth-does not & $2 \cdot 73$ & $3 \cdot 83$ \\
18 Adventurous-not adventurous & $1 \cdot 63$ & $2 \cdot 12$ \\
19 Hard-soft & $3 \cdot 30$ & $4 \cdot 41$ \\
20 Worries me-does not worry me & $4 \cdot 15$ & $5 \cdot 32$ \\
\hline
\end{tabular}

Analysis of the results by the matched pairs $t$-test (confirmed, in the case of grossly non-normal distributions, by the Wilcoxon matched pairs signed ranks test) showed significant differences in five of the twenty scales. Poisoning-children were more anxious $(P<0.008)$, harder $(P<0.01)$, and more active $(P<0.04)$ than controls. They also caused more worry $(P<0.004)$ and put things other than food more often in their mouths $(P<0.002)$.

In addition to information on the child's personality, parents were asked certain questions about their child's development. It was intended to collect detailed answers on this; however, it soon became apparent that the majority of parents could only remember accurately very basic developmental information. Because of this, the only data collected were the child's age of walking, and the age of becoming clean, dry by day and dry by night. The data were analysed by comparing by the $\chi^{2}$ test the number of pairs which had attainment of a milestone first in the poisoning-child with those where that milestone was reached first in the control member of the pair. The results are shown in Table 2. No significant differences were found between controland poisoning-children.

TABLE 2. Number of pairs with attainment earlier in $\chi^{2}$

\begin{tabular}{|c|c|c|c|}
\hline & Cases & Controls & \\
\hline $\begin{array}{l}\text { Walking } \\
\text { Clean } \\
\text { Dry by day } \\
\text { Dry by night }\end{array}$ & $\begin{array}{l}50 \\
32 \\
27 \\
18\end{array}$ & $\begin{array}{l}35 \\
42 \\
42 \\
31\end{array}$ & $\begin{array}{l}2.305^{*} \\
1.095^{*} \\
1.095(0.05<P<0.1)^{*} \\
2.937(0.05<P<0.1)^{*}\end{array}$ \\
\hline
\end{tabular}

* Non-significant.

The parents of poisoning-children and controls were also asked about aspects of the children's past medical history. Eight children had taken some sort of poison previously. Children with previous poisoning incidents were excluded from controls. Parents were asked about significant birth history (enough to cause admission of the child to a special care baby unit), significant medical history (enough to cause admission to hospital), and significant accidents (enough for the child to have been presented to some form of medical attention). The data were analysed by comparing by $\chi^{2}$ test those pairs with a factor in the medical history being present only in the cases, with those pairs where that factor was only present in the controls. The data are shown in Table 3.

Thus, there did not appear to be any differences between poisoning-children and controls as regards birth history. However, perhaps not surprisingly, poisoning-children had significantly more accidents than did controls, and had been admitted to hospital significantly more often than controls.

\section{Discussion}

There are difficulties in the assessment of personality in children under the age of 5 years and this survey, in fact, estimates what parents feel about their children's personality. Nevertheless, parents will know how a child behaves in his own environment, which is the relevant factor in childhood poisoning. It seems from the survey that certain child personality trends are factors in childhood

TABLE 3.

\begin{tabular}{lcccccc}
\hline & & & \multicolumn{3}{c}{ No. of pairs with factor present in $\chi^{2}$} \\
\cline { 5 - 7 } \multicolumn{1}{c}{ Foctor } & cases & No. in & controls & Cases & Controls \\
\hline Significant birth history & 13 & 7 & 12 & 6 & $1.389 *$ \\
Significant medical history & 25 & 12 & 21 & 8 & $4.966(P<0.03)$ \\
Accidents & 24 & 9 & 19 & 4 & $8.522(P<0.004)$ \\
\hline
\end{tabular}

* Non-significant. 
ingestion of poisons. The five significant factors are anxiety, hardness, ability to cause worry to parents, pica, and high activity. It is noteworthy that there was significantly more hyperactivity in the patients than in the controls in both Stewart's (1970) and Margolis's (1971) series. It may be that the hardness in the children in the present study corresponds to the destructiveness of the children in the Margolis study. Causing worry to parents may not be a valid scale, as the probands' parents were interviewed just after admission to hospital, and control parents visited at random. It is perhaps nor surprising that poisoning-children have an increased tendency to put things other than food in their mouths. However, what is perhaps more interesting is the poisoningchildren's greater anxiety than that of the controls, especially considering the highly significant amount of family stress (including parental anxiety) in the poisoning-families (Sibert, 1975).

The significantly greater history of accidents in the poisoning-children is to be expected, as ingestion of poisons is a form of accident. However, it is perhaps surprising that there was a significantly longer medical history of hospital admission in poisoningchildren than in controls. The developmental history of the poisoning-children did not differ from that of controls, which confirmed the results of Sobel (1971).

There is now good evidence that there are factors, particularly family stress, in the family, which predispose towards accidental ingestion of poisons (Sobel, 1971; Sibert, 1975; Julyan and Kuzemko, 1975). It appears from this and other surveys that some childhood personality trends, in particular hyperactivity and anxiety, are aetiological factors also. It may be that the interaction between the child's personality and the family's situation are important aetiologically. For instance, it is not too difficult to imagine an over-anxious, hyperactive child reacting to family stress by the abnormal behaviour of ingesting tablets.

\section{Acknowledgments}

We wish to thank Professor O. P. Gray and Professor $\mathbf{H}$. Campbell for their help and encouragement, and the consultant paediatricians in Cardiff for permission to study their patients. We also thank Mrs R. Bidder for her advice and Mrs M. Dauncey for retrieving information from the Cardiff Birth Survey.

\section{References}

BACKetT, E.M. \& Johnston, A.M. (1959) Social patterns of road accidents to children. British Medical Journal, 1, 409.

Baltimore, C. \& Meyer, R.J. (1969) A study of storage, child behavior traits and mother's knowledge of toxicology in 52 poisoned families and 52 comparison families. Pediatrics, 44, 816.

BURTON, L. (1968) Vulnerable Children, p. 32. Routledge and Kegan Paul, London.

JulyaN, M. \& KuZEMKo, J.A. (1975) Accidental poisoning in children: the 'sick family'. Practitioner, 214, 813.

MARGolis, R. (1971) A psychological study of childhood poisoning. A five-year follow-up. Pediatrics, 47, 439.

OsGood, G.E., Suci, G.T. \& TANenbaum, P. (1957) The Measurement of Meaning. University of Illinois Press, Urbana, Illinois.

Sarason, I.G. (1972) In: Personality. An Objective Approach, 2nd edn, pp. 287-289. John Wiley and Sons, New York.

SiberT, J.R. (1975) Stress in families of children who have ingested poisons. British Medical Journal, 3, 87.

Sobel, R. (1971) The psychiatric implications of accidental poisoning. Pediatric Clinics of North America, 17, 653.

Stewart, M.A., ThaCh, B.T. \& Freidin, A.B. (1970) Accidental poisoning and the hyperactive child syndrome. Diseases of the Nervous System, 31, 403. 